This provisional PDF corresponds to the article as it appeared upon acceptance. A copyedited and fully formatted version will be made available soon. The final version may contain major or minor changes.

\title{
Body composition analysis to study long-term training effects in elite male water polo athletes
}

Giovanni MELCHIORRI, Valerio VIERO, Roberto SORGE, Tamara TRIOSSI, Alessandro CAMPAGNA, Stella L. VOLPE, Dalgisio LECIS, Virginia TANCREDI, Angela ANDREOLI

The Journal of Sports Medicine and Physical Fitness 2017 Jun 21

DOI: 10.23736/S0022-4707.17.07208-5

Article type: Original Article

(c) 2017 EDIZIONI MINERVA MEDICA

Subscription: Information about subscribing to Minerva Medica journals is online at: http://www.minervamedica.it/en/how-to-order-journals.php

Reprints and permissions: For information about reprints and permissions send an email to: journals.dept@minervamedica.it - journals2.dept@minervamedica.it - journals6.dept@minervamedica.it 


\section{Body composition analysis to study long-term training effects in elite male water polo athletes.}

Giovanni Melchiorri, ${ }^{1,2}$; Valerio Viero*3; Roberto Sorge $^{1}$; Tamara Triossi ${ }^{3}$; Alessandro Campagna $^{4}$; Stella L. Volpe ${ }^{5}$, Dalgisio Lecis ${ }^{6}$; Virginia Tancredi ${ }^{1}$; Angela Andreoli ${ }^{6}$.

${ }^{1}$ School of Sport and Exercise Sciences, Department of Systems Medicine, Faculty of Medicine and Surgery, University of Roma Tor Vergata, Rome, Italy; ${ }^{2}$ Don Gnocchi Foundation IRCS, Milano, Italy; ${ }^{3}$ School of Sport and Exercise Sciences, Faculty of Medicine and Surgery, University of Roma Tor Vergata, Rome, Italy; ${ }^{4}$ Italian Swimming Federation; ${ }^{5}$ Department of Nutrition Sciences, College of Nursing and Health Professions, Drexel University; ${ }^{6}$ Human Physiology and Nutrition, University of Rome “Tor Vergata".

Corresponding author:

Valerio Viero

Via Braies, 64

00124 Roma

mobile phone: 00393384723601

fax: 00390633086459

email: valerio.viero@gmail.com 


\begin{abstract}
BACKGROUND: Elite water polo athletes undergo heavy training programs throughout the year, but especially to prepare major competitions, such as the Olympics. Optimal athletic performance is a result of many factors, including proper management of the intensity and volume of training, nutrition and recovery between training sessions. When training is excessive in relation to recovery may occur non functional overreaching (NFO). NFO can degenerate into overtraining syndrome (OTS) resulting in a decrease in athletic performance, with likely changes in body weight and body composition. The aim of this study was to evaluate the relationship between Body Composition (BC) and the tolerance to intense training supported by diet meal plans and to highlight any difference between athletes selected for the OG and not selected ones.
\end{abstract}

METHODS: Twenty-one male elite water polo athletes, 26 to 34 years of age, participated in the study. For three months before the Olympics, athletes have carried out an intense training period based on a detailed program. Only 13 athletes (OA) participated to OG, 8 were excluded (NOA). Body weight and height were measured and body mass index was calculated. BC and phase angle was evaluated at the half of first (T0), second (T1) and third (T2) month of training. Also blood analyses were collected at T0 and food intake assessed in all the evaluations. Measurements were carried out at three selected time points throughout the training period (12 weeks), which marked variations in the volume and intensity of the training load.

RESULTS: Data analyses showed no statistical difference among the three measurements performed for body weight, body composition and phase angle in all OA group. Furthermore, there was not statistically significant differences between the OA and NOA group for weight, body mass index, body composition and phase angle. 
CONCLUSIONS: Results of the present study encourage the use of body composition by bioelectrical impedance monitoring system for high-level athletes involved in long and intense training periods to prevent body dehydration and Overtraining Syndrome. Body Cell Mass monitoring provides a valuable help to evaluate the effects of training and to prevent any decrease in the performance level.

Key Words: Body Cell Mass, Body Mass Index, Athletes, Water polo, Diet 


\section{Introduction}

High-level sport, both in individual and team sports, involve international competitions. To prepare athletes for these competitions intense and long-lasting training is required. A high athletic performance is essential in most sport disciplines, therefore, during training, specific overload is placed on the components of the physiological systems to induce a stress response, which later results in compensatory adaptation. It is also well-known that proper feeding and rest are key factors for an effective training.

Water polo is a demanding sport that heavily taxes the aerobic and anaerobic pathways $^{1,2}$ and needs many hours of training, up to 35 hours a week. Athletes must be prepared for all the technical and tactical components of the game, and to be able to perform the required skills in an appropriate way they need an optimal physical condition. To get to the required level of performance, gym workouts with heavy overloads are performed and in water workouts also are tiring and prolonged. To participate in events like Olympic Games (OG), European Championships and World Championships, national teams have a long training that arrives and sometimes exceeds 12 weeks. Such lengthy periods and with such intense training stimuli involve the occurrence of specific conditions, some of these are searched for as functional overreaching (FO) and other unwanted and undesirable but possible when training is excessive in relation to recovery such as non functional overreaching (NFO). NFO can degenerate into overtraining syndrome (OTS) resulting in a decrease in athletic performance. ${ }^{3}$ Symptoms and signs indicating NFO and OTS conditions may be psychological and physiological; among them there is weight loss and dehydration, that of weight loss is an important component. The initial signs of the syndrome may become apparent only after a few weeks of overtraining.

Over the past 15 years, many researchers have extensively studied the effects of exercise-induced body weight loss and fluid loss on endurance performance and physiological 
functions. ${ }^{4,5}$ Properly evaluating hydration status is important for their relevant effects on both physical and mental performance and sport performance is therefore deeply affected. ${ }^{6}$

There is considerable interest in the evaluation of $\mathrm{BC}$ in exercise and sport, as it is known that $\mathrm{BC}$ is closely related with athletic performance and that exercise has the potential to modify BC. ${ }^{7}$ Moreover BC monitors fluid status (hydration), which is essential for the athlete's body functioning and a potential component of weight loss. Nonetheless, fluctuations in body weight can not be adequately interpreted unless the quantitative variations of the components (fat-free mass $[\mathrm{FFM}]$, fat mass $[\mathrm{FM}]$ and total body water [TBW]) are taken into account, because each component varies not dependently by the others. ${ }^{8}$ Among the other BC indicators there are the phase angle (PA) and the body cell mass (BCM). PA is an important parameter of $\mathrm{BC}$ that can give us information on the state of hydration, physical condition, integrity of cell membranes and lean body mass. The BCM, which includes fat-free mass (FFM) within the muscle, the intestines and the immune system, can be considered the most functionally important compartment in determining energy expenditure, protein needs and the metabolic response to stress ${ }^{9}$ and therefore is considered an effective indicator of the athlete's response to training, nutrition and rest. $\mathrm{BCM}$ has already been evaluated in football players, judo athletes and water polo athletes, ${ }^{10,11}$ but has not been evaluated in elite water polo athletes during a period of intensive training in preparation for OG. Furthermore, no data are available on the relationship between $\mathrm{BCM}$ and performance in longitudinal conditions in athletes.

Therefore, the aim of this study was to evaluate the relationship between $\mathrm{BC}$ and the tolerance to intense training supported by diet meal plans and to highlight any difference between athletes selected for the OG and not selected ones. 


\section{Materials and Methods}

Study Design

This is an observational and longitudinal study conducted in elite water polo players during the preparation for the 2016 OG. The study protocol was approved by the Ethics Committee of National Italian Federation and of the University of Rome "Tor Vergata", Rome, Italy.

Twenty-one male elite water polo athletes, 26 to 34 years of age, participated in the study. For three months before the Olympics, athletes have carried out an intense training period based on a detailed program. After OG, the data were analysed considering the athletes who participated in the $\mathrm{OG}(\mathrm{OA})$ and non-participating athletes (N-OA). BC and metabolic parameters were evaluated at the half of first (T0), second (T1) and third (T2) month of training. Measurements were carried out at three selected time points throughout the training period (12 weeks), which marked variations in the volume and intensity of the training load (Table1).

*** Table 1 about here $* * *$

Body Weight, Height, and Body Mass Index

Body weight was measured to the nearest $0.1 \mathrm{~kg}$ on an electronic beam scale, without clothes and shoes and after participants had voided. Height was measured to the nearest 0.5 cm using a Harpenden stadiometer. Body weight and height were measured twice per time point, and the average of the two measurements was used. Body mass index (BMI) was calculated as weight $(\mathrm{kg}) /$ height $\left(\mathrm{m}^{2}\right)$. 


\section{Body Composition Analysis}

Body composition was assessed using bioelectrical impedance analysis (BIA). BIA measurements were performed in the morning after an overnight fast of at least 12 hours and abstinence of alcohol consumption for 48 hours. Participants emptied their bladders within 30 minutes before undergoing the measurements. All measurements were performed on the dominant side, while participants lied supine on an examination table with limbs abducted away from the trunk. Four gel electrodes were attached on defined anatomical positions on the hand, wrist, ankle, and foot. ${ }^{12,13}$ The BIA measurements were performed using an Akern BIA (Florence, Italy) and Littmann 2325VP adhesive electrodes (3M, St. Paul, MN, USA). The BIA can measure resistance, reactance and phase angle (PA) and calculates: body cell mass (BCM), BCM-Index (BCM-I), fat free mass (FFM), fat mass (FM), total body water (TBW), extracellular water (ECW) and intracellular water (ICW). ${ }^{14}$ All measurements were performed using the same bioelectrical impedance analyzer, the same standard procedure described above and by the same expert operator.

\section{Blood collection and analysis}

At time 0 blood samples were collected after a 12-hour fast. Serum total cholesterol (TC), low-density lipoprotein cholesterol (LDL-C), serum high density lipoprotein cholesterol (HDL-C) and triglyceride (TG) concentrations and plasma glucose concentrations were evaluated to assess the initial nutritional status. Serum TC and TG concentrations were analysed by enzymatic methods (for serum TC concentrations: CHO-DPAP, Boehringer Mannheim, Mannheim, Germany; for serum TG concentrations: GPO-PAP, Roche Ltd, Basel, Switzerland). HDL-C and LDL-C concentrations were determined by direct methods (Wako Chemicals GmbH, Neuss, Germany for HDL-C; ABX Diagnostics, France for LDLC). Plasma glucose concentration was measured by photometric determination using the glucose dehydrogenase method (Roche Ltd). All blood parameters were analysed in duplicate. 
The coefficient of variation (CV) for each blood analysis parameter is as follows: serum $\mathrm{TC}<$ $3,8 \%$, LDL-C HDL $<5.0 \%$ and TG $<4 \%$.

Diet

All tested athletes were eating together, in the same place and following the same nutritional plan prepared by a nutritionist supported by the team doctor. The only freedom admitted, always within the nutritional plan, was in the choice of foods and in the quantities. The recommended diet was comprised of 55\% carbohydrate, $25 \%$ fat, $20 \%$ protein (of which about $50 \%$ made up of vegetable proteins) and $30 \mathrm{~g}$ of fibre, and followed the nutritional recommendations for water polo athletes. ${ }^{15}$ Total daily energy content of the diet was determined on an individual basis, being equal to $\pm 10 \%$ of the resting metabolic rate (RMR) ${ }^{16}$ plus energy for training and competitions.

To verify what they had eaten, at each assessment session athletes completed a food history questionnaire which included questions on vitamin and mineral supplementation and alcohol and cigarette use. ${ }^{17}$ The questionnaire had already been used in previous studies to estimate the caloric intake. ${ }^{18}$ The reported data are converted from foods to nutrients using food composition tables.

Statistical Analysis

Means and standard deviations (Mean \pm SD) for all variables were calculated. Repeated measures analysis of variance (ANOVA) and the Bonferroni post-hoc test were used to determine the impact of a long training period on specific haematological and biochemical parameters in elite male water polo players. SPSS (version 16.0) was used for all analysis. The significance level was set at $\mathrm{p}<0.05$. 


\section{Results}

According to participation to OG or not, athletes were divided into two groups, 13 Olympic athletes (OA) and 8 Non-Olympic athletes (N-OA).The anthropometric data of the two groups at $\mathrm{T} 0$ are listed in Table 2 . No statistic differences were found at $\mathrm{T} 0$ between the two groups.

*** Table 2 about here $* * *$

$\mathrm{BC}$ and PA of athletes in the different measurements are showed in Table 3. Group NOA was not assessed at T2 because already discarded. The data show that there were no statistically significant differences between OA and N-OA for BW, BMI, FFM, FM, TBW, ECW, and PA between the two groups and for longitudinal measurements.

*** Table 3 about here $* * *$

With regard to blood analysis, only LDL-C concentrations were significantly greater $(\mathrm{p}<0.001)$ in N-OA compared to OA. Blood analysis results are shown in Table 4 .

*** Table 4 about here $* * *$

\section{Discussion}

The aim of this observational study was to evaluate the relationship between the $\mathrm{BC}$ and the compliance to intense training during the preparation to $\mathrm{OG}$ and to highlight any 
difference between athletes selected and non selected for the OG. The study showed that by the $\mathrm{BC}$ assessment it is possible to monitor the positive effects of training and to prevent uncorrect feeding, dehydration and OTS risks. The tested athletes, as evidenced by training diaries and physical tests, carried out hard training for three months to properly prepare themselves to OG. Some of the athletes (NOA) have been excluded at the end of the second training month but no significant differences were detected, between this group and the OG participant (OA), in all tests carried out. Preparation strategies have been effective, as participation in the OG has led to the victory of an Olympic medal. The training program and the prescribed diet have maintained the Body Weight and BCM values of the athletes throughout the period. ICW values have been also maintained and BCM is an expression of ICW. A good level of BCM, or metabolic active mass, can be considered as a parameter for assessing individual performance capacities. It has been well established that BCM is related to oxygen consumption ( 8 to $10 \mathrm{~mL} / \mathrm{kg} / \mathrm{min}$ ) and energy expenditure ( 2.7 to $3.6 \mathrm{kcal} /$ hour $){ }^{17}$

PA represents the relationship between resistance and capacitive reactance of the body and is expressed in degrees; it is a parameter of the integrity of cell membranes and lean body mass and is associated with high reactance. A high PA value indicates high level of BCM or dehydration. In absence of the latter, thus, it is indicative of good physical fitness and therefore used in monitoring the athletes. Dehydration is a risk for water polo players who often train and play in indoor swimming pools with high temperatures and humidity levels. Furthermore, by training in water, they unlikely feel they are sweating. In this study, the PA value remains constant for OA group through all measurements. These results show a good level of athletic performance, which is consequence of a proper management of the workout volume and intensity and enough recovery between sessions. ${ }^{18}$ In fact workout, when is excessive compared to recovery time, causes NFO and then OTS, with consequent reduction in athletic performance. Given the intense and prolonged efforts that water polo requires in 
training and during the game, this risk of OTS is very high in players at this competitive level. Recent studies have shown some simple tools for monitoring early signs of OTS. ${ }^{19} \mathrm{BC}$, in particular through the BCM, ICW and PA parameters, is able to assess whether intense workout is going to target. Other information given by $\mathrm{BC}$ are about nutrition, hydration and recovery, providing useful advise to prevent OTS.

In talent-detection in water polo, as in other team sports, the anthropometric characteristics are very important. ${ }^{20,21}$ In our study BC and anthropometric characteristics had high values for the whole sample examined, with no statistically significant differences between OA and NOA. This confirms that in water polo, where physical contact is a frequent aspect of the game, high body mass value is an advantageous factor for players, especially in the high level. The lack of differences in all the tested parameters suggests that the choice of coaches in selecting players for OG was based more on technical and tactical parameters.

\section{Conclusions}

Results of the present study encourage the use of body composition by bioelectrical impedance monitoring system for high-level athletes involved in long and intense training periods to prevent body dehydration and Overtraining Syndrome. Body Cell Mass monitoring provides a valuable help to evaluate the effects of training and to prevent any decrease in the performance level. 


\section{References}

1. Smith, HK. Applied physiology of water polo. Sports Med 26: 317-334, 1998.

2. D'ercole C, Gobbi M, D'ercole A, Iachini F, Gobbi F. High intensity training for faster water polo. J Sports Med Phys Fitness. 2012 Jun;52(3):229-36.

3. Kreher JB, Schwartz JB. Overtraining syndrome: a practical guide. Sports Health. 2012 $\operatorname{Mar} ; 4(2): 128-38$.

4. Cheuvront SN, Carter R, Sawka MN. Fluid balance and endurance exercise performance. Curr Sports Med Rep. 2003;2:202-208.

5. Sawka MN, Burke LM, Eichner ER, et al. American College of Sports Medicine position stand. Exercise and fluid replacement. Med Sci Sports Exerc. 2007;39:377-390.

6. Maughan RJ, Meyer NL. Hydration during intense exercise training. Nestle Nutr Inst Workshop Ser. 2013;76:25-37. doi: 10.1159/000350225. Epub 2013 Jul 25.

7. Kraemer WP, Volek JS, Clark KL et al (1999) Influence of exercise training on physiological and performance changes with weight loss in men. Med Sci Sports Exerc 31(9):1320-1329. 
8. Andreoli A, Monteleone M, Van Loan M, Promenzio L, Tarantino U, De Lorenzo A (2001) Effects of different sports on bone density and muscle mass in highly trained athletes. Med Sci Sports Exerc 33:507-511.

9. Roubenoff R (1999). The pathophysiology of wasting in the elderly. J Nutr 129, 256S259S.

10. Melchiorri G, Monteleone G, Andreoli A et al (2007) Body cell mass measured by bioelectrical impedance spectroscopy in professional football (soccer) players. J Sports Med Phys Fitness 47(4):408-412

11. Andreoli A, Melchiorri G, Brozzi M, Di Marco A, Volpe SL, Garofano P, Di Daniele N, De Lorenzo (2003) Effect of different sports on body cell mass in highly trained athletes. Acta Diabetol 40 (Suppl 1):S122-S125

12. Kyle UG, Bosaeus I, De Lorenzo AD, Deurenberg P, Elia M, Gomez JM et al. (2004a). Composition of the ESPEN Working Group. Bioelectrical impedance analysispart I: review of principles and methods. Clin Nutr 23, 1226-1243.

13. Kyle UG, Bosaeus I, De Lorenzo AD, Deurenberg P, Elia M, Manuel Gomez J et al. (2004b). Bioelectrical impedance analysis-part II: utilization in clinical practice. Clin Nutr $23,1430-1453$.

14. De Lorenzo A, Andreoli A, Matthie J, Withers P (1997) Predicting body cell mass with bioimpedance by using theoretical methods:a technological review. J Appl Physiol $82: 1542-1558$. 
15 Cox GR, Broad EM, Riley MD, Burke LM. Body mass changes and voluntary fluid intakes of elite level water polo players and swimmers. J Sci Med Sport. 2002 Sep;5(3):183-93.

16. De Lorenzo A, Tagliabue A, Andreoli A, Testolin G, Comelli M, Deurenberg P (2001). Measured and predicted resting metabolic rate in Italian males and females, aged 18-59 y. Eur J Clin Nutr 55, 208-214.

17. Porrini M, Gentile MG, Fidanza F. Biochemical validation of a self-administered semi-quantitative food-frequency questionnaire. Br J Nutr. 1995 Sep;74(3):323-33.

18. Vicennati V, Pasqui F, Cavazza C, Garelli S, Ccasadio E, Di Dalmazi G, Pagotto U, Pasquali R. Cortisol, energy intake, and food frequency in overweight/ obese women. Nutrition 2010; Oct 8.

19 Kinney JM, Lister J, Moor FD (1963). Relationship of energy expenditure to total exchangeable potassium. Ann NY Acad Sci 110, 711-722.

20. Goulet ED. Dehydration and endurance performance in competitive athletes. Nutr Rev. 2012 Nov;70 Suppl 2:S132-6. doi: 10.1111/j.1753-4887.2012.00530.x.

21. Gregory R. Cox, Iñigo Mujika, and Cees-Rein van den Hoogenband. Nutritional Recommendations for Water Polo. International Journal of Sport Nutrition and Exercise Metabolism, 2014, 24, 382 -391 C 2014 Human Kinetics, Inc.

22. Pyne DB, Sharp RL. Physical and energy requirements of competitive swimming events Int J Sport Nutr Exerc Metab. 2014 Aug;24(4):351-9. doi:10.1123/ijsnem.20140047. Epub 2014 Jul 14. 
23. Carfagno DG, Hendrix JC 3rd. Overtraining syndrome in the athlete: current clinical practice. Curr Sports Med Rep. 2014 Jan-Feb;13(1):45-51. doi: 0.1249/JSR.000027.

24. Sekulic D1, Kontic D, Esco MR, Zenic N, Milanovic Z, Zvan M. Sport-Specific Conditioning Variables Predict Offensive and Defensive Performance in High-Level Youth Water Polo Athletes.J Strength Cond Res. 2016 May;30(5):1316-24. doi: 10.1519/JSC.0000000000001213.

25. Sheppard JM, Gabbett TJ, Stanganelli LC. An analysis of playing positions in elite men's volleyball: considerations for competition demands and physiologic characteristics. J Strength Cond Res. 2009 Sep;23(6):1858-66).

26. Miran Kondrič, Ognjen Uljević, Goran Gabrilo, Dean Kontić, Damir Sekulić. General Anthropometric and Specific Physical Fitness Profile of High-Level Junior Water Polo Players. Journal of Human Kinetics volume 32/2012, 157-165 DOI: 10.2478/v10078012-0032- 


\section{TITLES OF TABLES}

Table1. Volume and intensity of the training load.

Table 2. Anthropometric characteristics of the athletes.

Table 3. Body composition and phase angle of the athletes.

Table 4. Blood analysis results

\section{TITLES OF IMAGES}

Figure 1. Aerobic and Anaerobic metabolism. 
Table1. Volume and intensity of the training load.

\begin{tabular}{cccc}
\hline & T0 & T1 & T2 \\
& $(\%)$ & $(\%)$ & $(\%)$ \\
\hline AE & 38 & 40 & 25 \\
AE-AN & 24 & 0 & 25 \\
AN-L & 28 & 10 & 22 \\
AN-ALA & 5 & 20 & 12 \\
match & 5 & 30 & 16 \\
\hline
\end{tabular}

Table 1: $\mathrm{T} 0=$ First training month; $\mathrm{T} 1=$ Second training month; $\mathrm{T} 2=$ Third training month; $\mathrm{AE}=$ Aerobic; $\mathrm{AE}-\mathrm{AN}=$ Aerobic-anaerobic; $\mathrm{AN}-\mathrm{L}=$ Anaerobic-lactate; AN-ALA= Anaerobic-alactic. 
Table 2. Anthropometric characteristics of the athletes.

\begin{tabular}{lcccc}
\hline & Total & OA & NOA & \\
& $(\mathrm{N}=21)$ & $(\mathrm{N}=13)$ & $(\mathrm{N}=8)$ & $p$ \\
\hline Mean $\pm \mathrm{sd}$ & Mean $\pm \mathrm{sd}$ & Mean $\pm \mathrm{sd}$ & \\
Age (years) & $28,77 \pm 4,38$ & $29,69 \pm 3,38$ & $27,44 \pm 5,48$ & 0,246 \\
Weight $(\mathrm{Kg})$ & $95,63 \pm 7,88$ & $95,72 \pm 7,55$ & $95,43 \pm 7,84$ & 0,655 \\
Height $(\mathrm{m})$ & $188,23 \pm 6,69$ & $190,00 \pm 5,54$ & $185,67 \pm 7,68$ & 0,139 \\
BMI $(\mathrm{Kg} / \mathrm{m} 2)$ & & & \\
& $26,96 \pm 1,97$ & $26,56 \pm 2,00$ & $27,48 \pm 1,82$ & 0,439 \\
\hline
\end{tabular}

Table 2: Total $=\mathrm{OA}+\mathrm{NOA} ; \mathrm{OA}=$ Athletes selected for the Olympic Games; $\mathrm{NOA}=$ Athletes non selected for the OG. 
Table 3. Body composition and phase angle of the athletes.

\begin{tabular}{|c|c|c|c|c|c|c|}
\hline & & $\mathrm{OA}$ & & & & \\
\hline & T0 & $\mathrm{T} 1$ & $\mathrm{~T} 2$ & T0 & $\mathrm{T} 1$ & \\
\hline & $(\mathrm{N}=13)$ & $(\mathrm{N}=13)$ & $(\mathrm{N}=13)$ & $(\mathrm{N}=8)$ & $(\mathrm{N}=8)$ & \\
\hline & Mean \pm SD & Mean \pm SD & Mean \pm SD & Mean \pm SD & Mean \pm SD & $p$ \\
\hline FFM & & & & & &, $802 *$ \\
\hline$(\mathrm{kg})$ & $77,30 \pm 5,51$ & $76,01 \pm 6,98$ & $75,83 \pm 6,90$ & $77,15 \pm 7,25$ & $75,84 \pm 7,71$ &, $946^{\wedge}$ \\
\hline FM & & & & & &, $597^{*}$ \\
\hline$(\mathrm{kg})$ & $18,42 \pm 5,50$ & $19,35 \pm 4,79$ & $19,78 \pm 4,32$ & $18,29 \pm 4,54$ & $20,20 \pm 4,12$ &, $831^{\wedge}$ \\
\hline FM & & & & & & ,480* \\
\hline$(\%)$ & $19,1 \pm 4,7$ & $20,246 \pm, 38$ & $20,662 \pm 3,96$ & $18,6 \pm 4,8$ & $20,1 \pm 4,5$ &, $610^{\wedge}$ \\
\hline $\mathrm{BCM}$ & & & & & & ,960* \\
\hline$(\mathrm{kg})$ & $48,11 \pm 3,23$ & $47,38 \pm 4,20$ & $47,52 \pm 4,48$ & $47,84 \pm 3,96$ & $47,90 \pm 4,94$ &, $931^{\wedge}$ \\
\hline TBW & & & & & &, $809 *$ \\
\hline$(\mathrm{kg})$ & $56,58 \pm 4,02$ & $55,65 \pm 5,10$ & $55,51 \pm 5,05$ & $56,46 \pm 5,31$ & $55,54 \pm 5,67$ &, $949^{\wedge}$ \\
\hline$\overline{\mathrm{ECW}}$ & & & & & &, $656^{*}$ \\
\hline$(\mathrm{kg})$ & $21,59 \pm 2,60$ & $21,17 \pm 2,40$ & $20,99 \pm 2,29$ & $21,66 \pm 2,67$ & $20,72 \pm 2,44$ &, $826^{\wedge}$ \\
\hline ICW & & & & & &, $855^{*}$ \\
\hline$(\mathrm{kg})$ & $34,987 \pm 2,27$ & $34,467 \pm 3,04$ & $34,535 \pm 3,20$ & $34,953 \pm 3,1$ & $34,908 \pm 4,10$ &, $951^{\wedge}$ \\
\hline PA & & & & & &, $597 *$ \\
\hline$\left({ }^{\circ}\right)$ & $8,02 \pm 0,84$ & $8,02 \pm 0,48$ & $8,09 \pm 0,60$ & $7,94 \pm 0,58$ & $8,04 \pm 0,57$ &, $831^{\wedge}$ \\
\hline
\end{tabular}

Table 3: $\mathrm{OA}=$ Athletes selected for the Olympic Games; NOA=Athletes non selected for the OG. $\mathrm{T} 0=$ First training month; $\mathrm{T} 1=$ Second training month; $\mathrm{T} 2=$ Third training month. $\mathrm{FFM}=$ Free Fat Mass; FM= Fat Mass; $\mathrm{BCM}=$ Body Cell Mass; TBW= Total Body Water; ECW= Extra Cellular Water; ICW $=$ Intra Cellular Water; $\mathrm{PA}=$ Phase Angle. ${ }^{*}=$ along time; ${ }^{\wedge}=$ between groups. 
Table 4. Blood analysis results

\begin{tabular}{|c|c|c|c|c|}
\hline & $\begin{array}{l}\text { Totali } \\
(\mathrm{N}=\mathbf{2 1})\end{array}$ & $\begin{array}{c}\text { OA } \\
(\mathrm{N}=13)\end{array}$ & $\begin{array}{l}\text { NOA } \\
(\mathrm{N}=8)\end{array}$ & $p$ \\
\hline & $\operatorname{Mean} \pm$ sd & $\operatorname{Mean} \pm$ sd & $\operatorname{Mean} \pm$ sd & \\
\hline Total Cholesterol (mg/dl) & $192,71 \pm 27,35$ & $187,96 \pm 20,97$ & $198,81 \pm 34,74$ & 0,450 \\
\hline HDL (mg/dl) & $57,36 \pm 15,67$ & $61,93 \pm 16,12$ & $51,48 \pm 13,99$ & 0,195 \\
\hline LDL (mg/dl) & $112,07 \pm 20,42$ & $101,23 \pm 13,58$ & $126,01 \pm 19,85$ & 0,010 \\
\hline Triglyceride (mg/dl) & $147,18 \pm 109,50$ & $128,99 \pm 80,03$ & $170,57 \pm 142,49^{*}$ & 0,470 \\
\hline Glycaemia (mg/dl) & $96,14 \pm 7,71$ & $94,85 \pm 3,55$ & $97,80 \pm 11,23$ & 0,466 \\
\hline $\operatorname{Azotaemia}(m g / d l)$ & $44,99 \pm 6,97$ & $43,21 \pm 4,47$ & $47,27 \pm 9,17$ & 0,261 \\
\hline Creatinine (mg/dl) & $2,52 \pm 1,00$ & $4,47 \pm 1,33$ & $1,03 \pm 0,09$ & 0,396 \\
\hline Serum Iron (mg/dl) & $92,47 \pm 27,84$ & $97,11 \pm 35,69$ & $86,50 \pm 12,83$ & 0,496 \\
\hline Uricaemia (mg/dl) & $5,42 \pm 0,74$ & $5,20 \pm 0,73$ & $5,72 \pm 0,70$ & 0,208 \\
\hline NA (mmol/l) & $146,29 \pm 1,79$ & $146,25 \pm 1,48$ & $146,33 \pm 2,13$ & 0,937 \\
\hline K (mmol/l) & $4,66 \pm 0,29$ & $4,679 \pm 0,290$ & $4,641 \pm 0,314$ & 0,808 \\
\hline $\mathrm{Ca}(\mathrm{mg} / \mathrm{dl})$ & $9,58 \pm 0,22$ & $9,57 \pm 0,20$ & $9,58 \pm 0,27$ & 0,951 \\
\hline $\mathrm{Cl}(\mathrm{mmol} / \mathrm{l})$ & $107,93 \pm 1,53$ & $107,79 \pm 1,60$ & $108,10 \pm 1,55$ & 0,700 \\
\hline $\operatorname{Mg}(\mathrm{ug} / \mathrm{dl})$ & $2,01 \pm 0,08$ & $2,02 \pm 0,09$ & $1,99 \pm 0,05$ & 0,360 \\
\hline$P(\mathrm{mg} / \mathrm{dl})$ & $4,33 \pm 0,60$ & $4,44 \pm 0,50$ & $4,18 \pm 0,71$ & 0,407 \\
\hline Red Blood Cells $\left(10^{\wedge} 6 / \mathbf{u L}\right)$ & $4,93 \pm 0,28$ & $4,97 \pm 0,29$ & $4,88 \pm 0,29$ & 0,588 \\
\hline White Blood Cells $\left(10^{\wedge} 3 / u_{L}\right)$ & $6,46 \pm 0,91$ & $6,74 \pm 1,06$ & $6,02 \pm 0,55$ & 0,175 \\
\hline Lymphocytes (\%) & $37,38 \pm 5,70$ & $35,07 \pm 5,98$ & $40,45 \pm 3,85$ & 0,080 \\
\hline $\mathrm{HB}(\mathrm{g} / \mathrm{dl})$ & $14,56 \pm 0,84$ & $14,72 \pm 0,83$ & $14,33 \pm 0,87$ & 0,408 \\
\hline Platelets $\left(10^{\wedge} 3 / \mathbf{u L}\right)$ & $213,71 \pm 34,08$ & $216,00 \pm 40,69$ & $210,67 \pm 26,07$ & 0,785 \\
\hline CPK (U/l) & $366,33 \pm 196,38^{*}$ & $408,11 \pm 216,59^{*}$ & $303,67 \pm 158,35^{*}$ & 0,331 \\
\hline Bilirubin (mg/dl) & $0,56 \pm 0,28$ & $0,66 \pm 0,32$ & $0,42 \pm 0,14$ & 0,116 \\
\hline
\end{tabular}


Figure 1. Aerobic and Anaerobic metabolism.

\begin{tabular}{|c|c|c|c|c|c|c|}
\hline \multirow{3}{*}{$\begin{array}{l}\text { Time for } \\
\text { various } \\
\text { fuels }\end{array}$} & \multicolumn{2}{|c|}{$\begin{array}{l}\text { Anaerobic } \\
\text { Produce ATP with no oxygen supply }\end{array}$} & \multicolumn{4}{|c|}{$\begin{array}{l}\text { Aerobic } \\
\text { Produce ATP with oxygen supply }\end{array}$} \\
\hline & $\begin{array}{l}\text { Alactic } \\
\text { CP system } \\
\text { ATP/CP stored in } \\
\text { muscles }\end{array}$ & $\begin{array}{l}\text { Lactic } \\
\text { Lactate system } \\
\text { Glycogen (Lactate as } \\
\text { byproduct) }\end{array}$ & Carbs & & Fat & Protein \\
\hline & $10 \mathrm{~s}$ & $40 s$ & $2 \mathrm{~min} 6 \mathrm{~min}$ & $25 \mathrm{~min}$ & $1 \mathrm{hr}$ & $2 \mathrm{hrs}$ \\
\hline
\end{tabular}

